Courrier du Centre International Blaise-

Pascal

$36 \mid 2014$

Varia

\title{
Pascal à Alexandrie
}

\section{Emmanuel Nyandwi}

\section{OpenEdition}

Journals

Édition électronique

URL : https://journals.openedition.org/ccibp/317

DOI : $10.4000 /$ ccibp.317

ISSN : 2493-7460

\section{Éditeur}

Centre international Blaise Pascal

\section{Édition imprimée}

Date de publication : 5 février 2014

Pagination : 27-28

ISBN : 978-2-84516-693-6

ISSN : 0249-6674

Référence électronique

Emmanuel Nyandwi, «Pascal à Alexandrie », Courrier du Centre International Blaise-Pascal [En ligne], 36 2014, mis en ligne le 03 décembre 2015, consulté le 28 juin 2022. URL : http://

journals.openedition.org/ccibp/317 ; DOI : https://doi.org/10.4000/ccibp.317

Ce document a été généré automatiquement le 29 septembre 2020.

Centre international Blaise Pascal 


\section{Pascal à Alexandrie}

\section{Emmanuel Nyandwi}

Affiche de la journée d'étude "Blaise Pascal l'homme et l'œuvre" (1623-1662)

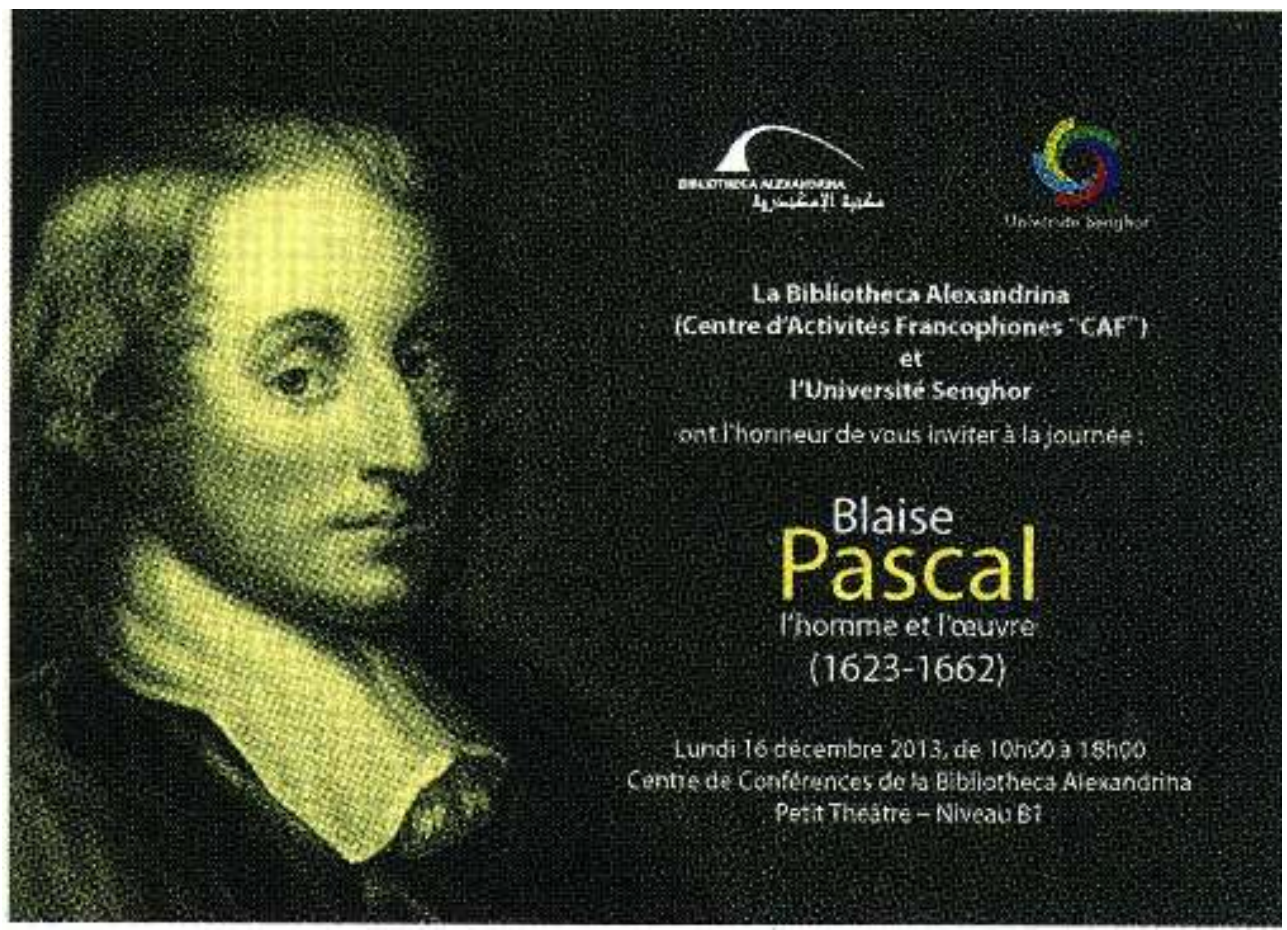

Lundi 16 décembre 2013, Centre de Conférences de la Bibliothéca Alexandrina

1 Le 16 décembre 2013 a eu lieu, dans le cadre impressionnant de la Bibliotheca Alexandrina, une journée Blaise Pascal organisée conjointement par cette prestigieuse institution, que dirige le professeur Ismail Serageldin, et par l'Université internationale Senghor, qui forme sous la direction du professeur Albert Lourde plus d'un millier d'étudiants au service du développement de l'Afrique. L'événement s'est déroulé sous le patronage du Centre d'activités francophones récemment créé à la Bibliotheca Alexandrina et qui, sous l'impulsion de Madame Marwa El Sahn, docteur de l'Université 
Paris VIII, a pour mission de promouvoir la culture francophone à l'échelle locale et régionale tout en tissant un réseau de partenariats internationaux d'excellence.

2 Après la cérémonie d'ouverture, où le professeur Ismail Serageldin mit en lumière la portée de l'exemple pascalien, génie de la langue française et simultanément génie universel, une table ronde orchestrée par Jean-François Fau, directeur du département Culture de l'Université Senghor, réunit sur le thème "Pascal entre diversité et complexité » trois intervenantes: Nayla Fahed, professeur à la Faculté des Lettres et Sciences humaines de l'Université Saint-Joseph de Beyrouth, décrivit "L'homme écartelé dans les Pensées de Pascal »; Nayla Tamraz, chef du Département de lettres françaises de cette même Université, retraça les liens unissant Pascal, Philippe de Champaigne et Port-Royal; et Véronique Rieffel, directrice de l'Institut français d'Égypte à Alexandrie, se livra à une «Analyse comparée des films Blaise Pascal de Roberto Rossellini et Ma nuit chez Maud d'Éric Rohmer ». L'après-midi commença par la conférence de Gérard Ferreyrolles, professeur à l'Université Paris-Sorbonne, sur « La politique dans les Pensées de Pascal », qui suscita avec le public nombreux des échanges manifestant l'actualité des analyses pascaliennes sur la saine distinction de l'ordre politique et de l'ordre religieux. Place ensuite au spectacle et à la cérémonie de clôture. Le spectacle en fait fut double, voire triple. Il se composa d'abord d'une très vivante lecture de textes pascaliens réalisée par les étudiants de l'Université Senghor dirigés par le metteur en scène africain, Abdoulaye Abdoul Oumate, puis d'une étonnante représentation théâtrale inspirée de Pascal par deux toutes jeunes égyptiennes, élèves à l'Institution Sainte-Jeanne Antide, Malak Tolba et Nada Abdel Salam. L'originalité atteignit son comble lorsque des étudiants de l'Université Senghor furent appelés sur scène pour réaliser en direct devant les spectateurs et dans un temps limité à dix minutes chacun un portrait de Pascal. Enfin furent proclamés les résultats du concours lancé plusieurs semaines auparavant et qui consistait à « écrire un article ou réaliser une œuvre artistique mettant en relief Pascal, sa vie et la diversité des domaines de sa production intellectuelle ». Deux lauréats scolaires, deux lauréats des premiers cycles universitaires et deux lauréats du $3^{\mathrm{e}}$ cycle furent ainsi récompensés par des prix et des certificats de reconnaissance, au milieu des applaudissements nourris de leurs familles, camarades et professeurs.

3 Au total, une manifestation particulièrement riche et réussie, qui associait aux interventions d'enseignants universitaires la participation d'étudiants et même d'élèves dans une atmosphère à la fois studieuse et festive. C'est un signe extrêmement positif et encourageant pour l'avenir non seulement de la francophonie mais de l'humanisme que cette audacieuse initiative du $\mathrm{D}^{\mathrm{r}}$. Marwa El Sahn, pleinement couronnée de succès, autour d'une figure comme celle de Pascal qui décidément, comme le disait le professeur Serageldin, « appartient au monde entier ». 
INDEX

Mots-clés : Pascal

Index géographique : Alexandrie 